BMJ Open

Diabetes

Research

\& Care

\title{
Cholinesterase inhibitors in patients with diabetes mellitus and dementia: an open-cohort study of $\sim 23000$ patients from the Swedish Dementia Registry
}

\author{
Juraj Secnik (1) , ${ }^{1}$ Emilia Schwertner, ${ }^{1}$ Michael Alvarsson, ${ }^{2}$ Niklas Hammar, ${ }^{3}$ \\ Johan Fastbom, ${ }^{4}$ Bengt Winblad, ${ }^{5,6}$ Sara Garcia-Ptacek, ${ }^{1,6,7}$ Dorota Religa, ${ }^{1,6}$ \\ Maria Eriksdotter ${ }^{1,6}$
}

To cite: Secnik J, Schwertner E, Alvarsson M, et al.

Cholinesterase inhibitors in patients with diabetes mellitus and dementia: an open-cohort study of $\sim 23000$ patients from the Swedish Dementia Registry. BMJ Open Diab Res Care 2020;8:e000833. doi:10.1136/ bmjdrc-2019-000833

- Additional material is published online only. To view please visit the journal online (http://dx.doi.org/10.1136/ bmjdrc-2019-000833).

DR and ME contributed equally.

Received 16 August 2019 Revised 24 November 2019 Accepted 28 November 2019

Check for updates

(c) Author(s) (or their employer(s)) 2020. Re-use permitted under CC BY-NC. No commercial re-use. See rights and permissions. Published by BMJ.

For numbered affiliations see end of article.

Correspondence to Dr Juraj Secnik; juraj.secnik@ki.se

\section{ABSTRACT}

Objective Cholinesterase inhibitors (ChEls) and memantine are the only approved pharmacological treatments for Alzheimer's disease (AD). Recent literature suggests reductions in cardiovascular burden and risk of stroke in ChEI users. However, the clinical effectiveness of these drugs in patients with diabetes mellitus (DM) and dementia has not been evaluated.

Research design and methods We conducted a registrybased open-cohort study of 22660 patients diagnosed with $A D$ and mixed-pathology dementia registered in the Swedish Dementia Registry until December 2015. Information on drug use, comorbidity and mortality was extracted using the linkage with the National Patient Registry, the Prescribed Drug Registry and the Cause of Death Registry. In total, 3176 (14\%) patients with DM and 19484 patients without DM were identified. Propensity-score matching, Cox-regression and competingrisk regression models were applied to produce HRs with $95 \%$ Cls for differences in all-cause, cardiovascular and diabetesrelated mortality rates in ChEl users and non-users. Results After matching the ChEl use in patients with DM was associated with $24 \%$ all-cause mortality reduction (HR 0.76 (95\% Cl 0.67 to 0.86$))$, compared with $20 \%$ reduction ( 0.80 (0.75 to 0.84)) in non-DM users. Donepezil and galantamine use were associated with a reduced mortality in both patients with $\mathrm{DM}$ (0.84 (0.74 to 0.96$) ; 0.80$ (0.66 to 0.97$)$ ) and patients without DM ( 0.85 ( 0.80 to 0.90$) ; 0.93$ ( 0.86 to $0.99))$. Donepezil was further associated with reduction in cardiovascular mortality, however only in patients without DM (0.84 (0.75 to 0.94$))$. Rivastigmine lowered mortality only in the whole-cohort analysis and in patients without DM $(0.82$ (0.75 to 0.89)). Moreover, ChEl use was associated with $48 \%$ reduction in diabetes-related mortality (HR 0.52 (0.32 to 0.87)) in the whole-cohort analysis. Last, low and high doses were associated with similar benefit.

Conclusions We found reductions in mortality in patients with $\mathrm{DM}$ and $\mathrm{AD}$ or mixed-pathology dementia treated with ChEls, specifically donepezil and galantamine were associated with largest benefit. Future studies should evaluate whether ChEls help maintain self-management of diabetes in patients with dementia.

\section{INTRODUCTION}

Increasing life-expectancy brings new challenges to the ageing populations, and

\section{Significance of this study}

What is already known about this subject?

- Cholinesterase inhibitors and memantine are currently the only pharmacological treatment of Alzheimer's disease and mixed-pathology dementia.

- Prior studies have suggested beneficial effects of cholinesterase inhibitors on cardiovascular, cerebrovascular and care-related outcomes.

- Patients with diabetes mellitus and dementia were previously found less likely to receive cholinesterase inhibitors in comparison to patients without diabetes.

What are the new findings?

- Patients with diabetes and dementia were less commonly treated with cholinesterase inhibitors; however, the reductions in mortality associated with their use were significant and similar to patients without diabetes. Contrary to previous findings, no doseresponse effect was observed.

- Among the specific cholinesterase inhibitors, donepezil and galantamine had overall positive effect on mortality among patients with diabetes.

- Reduction in diabetes-related mortality was associated with cholinesterase inhibitor use, while cardiovascular mortality was not significantly modified in patients with diabetes and dementia.

How might these results change the focus of research or clinical practice?

- Use of cholinesterase inhibitors in patients with diabetes and dementia seem to positively affect patient survival, with donepezil and galantamine associated with the largest survival benefit, while higher doses did not seem to exhibit further advantage overall. However, we are aware of the Cls being relatively close to unity and the presence of residual confounding; thus, the study cannot substitute a randomized clinical trial.

- Consequently, we believe further exploration of the interaction between cholinesterase inhibitors and diabetes outcomes is warranted.

tackling multimorbidity is a global priority. Both dementia and diabetes mellitus (DM) frequently coexist, as $13 \%-20 \%$ of patients 
with dementia suffer also from DM. ${ }^{2} \mathrm{DM}$ is a wellestablished risk factor for dementia ${ }^{3}$ however, the quality of dementia care when DM is present warrants further research. Moreover, the current DM standards-of-care do not address the DM-dementia coexistence in detail, restricting the recommendations to periodic screening for cognitive decline and individualized approach. ${ }^{4}$ However, individualizing treatment requires high-quality studies focusing on the interplay between pharmacological treatment and clinical care of both DM and dementia.

Current treatment of Alzheimer's disease (AD) is symptomatic and limited to acetylcholinesterase inhibitors (ChEI) and the NMDA-receptor antagonist memantine. ChEI provide a modest, but significant effect on cognition; however, few studies have considered their long-term use. ${ }^{56}$ Moreover, several studies have found improved survival and positive changes in the relative risks for cardiovascular events in ChEI-treated patients with dementia. ${ }^{7-9}$ On the other hand, the increased incidence of hypotension, falls and gastrointestinal sideeffects may counterbalance their protective effect. ${ }^{10}$ Moreover, previous studies have not taken into account discontinuation of treatment after dementia diagnosis, nor have ChEI been evaluated in the subpopulation of patients with DM, which suffer from higher rates of mortality, stroke and cardiovascular events.

In addition, although the specific ChEI drugs have similar mechanism of action, they differ in pharmacological properties and targets. Donepezil is a selective and reversible ChEI ${ }^{11}$ while rivastigmine is slowly reversible, inhibits both acetylcholinesterase and butyrylcholinesterase, ${ }^{12}$ and is available as oral treatment and transdermal patch. Galantamine is rapidly reversible, and additionally acts as an allosteric modulator of the nicotinic cholinergic receptors. ${ }^{13}$ Thus, it is plausible that some ChEI drugs may be more suitable for patients with DM than others.

Our research group has previously shown that Swedish patients with $\mathrm{DM}$ with $\mathrm{AD}$ or mixed-pathology dementia received significantly less ChEI than their non-DM counterparts, ${ }^{14}$ suggesting inadequate clinical management. ${ }^{15}$ It is possible that the generally higher burden of vascular pathology and high number of prescribed drugs could potentially affect the decision to treat patients with DM with ChEI. However, AD is still the most common dementia disorder in patients with $\mathrm{DM},{ }^{16}$ thus the absence of ChEI treatment is not optimal for these patients.

This study had three objectives: (1) assess all-cause, cardiovascular and diabetes-related mortality in patients with DM with dementia who were prescribed ChEI up to 9 years after dementia diagnosis; (2) assess the mortality rates in ChEI-treated patients with DM compared with their non-DM counterparts; (3) determine differences among specific ChEI drugs and their prescribed dose.

\section{METHODS}

Data sources

This registry-based open-cohort study was performed using the information from four Swedish registries, which are described below. The Swedish Personal Identification Number was used to identify patients across registries. Data merging was performed by a separate government entity (National Board of Health and Welfare).

The primary study inclusion criterion was dementia diagnosis with exclusion criteria comprising incorrect or missing data on key variables, or irrelevant dementia types (online supplementary figure 1).

\section{Swedish Dementia Registry (SveDem)}

SveDem is a Swedish quality-of-care registry and has been thoroughly described previously. ${ }^{17}$ Briefly, SveDem was established in 2007 with the purpose to register all patients with dementia in Sweden at the time of dementia diagnosis and annual follow-ups. It stores data on clinical characteristics (eg, Mini-Mental State Examination (MMSE)), sociodemography (eg, living arrangements), community support (eg, homecare) and general pharmacological management of patients with dementia. ${ }^{17}$ Dementia disorders recorded in SveDem include AD, mixedpathology dementia (both $\mathrm{AD}$ and vascular pathology present), vascular dementia, dementia with Lewy Bodies, frontotemporal dementia, Parkinson's disease dementia, unspecified dementia (uncertain dementia type) and other dementia types (eg, corticobasal degeneration). As of 2017, more than 70000 patients with dementia have been registered, which makes SveDem the largest dementia registry in the world. ${ }^{18}$

In the present study, we included patients recorded in SveDem until December 31, 2015 and diagnosed with AD or mixed-pathology dementia.

\section{Swedish Prescribed Drug Registry (Drug Registry)}

The Drug Registry was established in July 2005 and includes data on all dispensed drug prescriptions at Swedish Pharmacies to the entire Swedish population. ${ }^{19}$ The pharmacological records are coded according to the Anatomical Therapeutic and Chemical (ATC) classification. We extracted the drug data below since the start of the registry until December 31, 2015.

Patients were considered users of ChEI medications (ATC codes N06DA, N06DA02, N06DA03 and N06DA04) if the first date of prescription fill of ChEI ATC codes were recorded by the Drug Registry at the time of dementia diagnosis or in the yearly periods after dementia diagnosis (up to 9years).

Two approaches to exposure status were used-wholecohort analysis and propensity-score (PS) matched analysis.

\section{Whole-cohort analysis}

Patients with recorded ChEI usage at the time of dementia diagnosis were considered exposed at the start of follow-up. Patients who received medication after dementia diagnosis but were not ChEI users at the time of dementia diagnosis were considered unexposed until the date of first withdrawal of drug from the pharmacy (=prescription fill). If no date was recorded, patients were unexposed until the study end. 
Moreover, in the ChEI class analysis, the patients were considered exposed if a date of first prescription fill was present in the individual yearly intervals, with exposure lasting until the first prescription fill date in the next yearly interval (with exposure continuing in the following interval). Also, patients were kept exposed for 1year after the last known fill date if no next prescription fill was observed. After this 1year, patients were considered unexposed. This was done to account for other fills in the interval and the possibility of stockpiling medications by patients. Patients were transferred to the exposed group, if they had filled a prescription after an unexposed period.

For specific-drug analysis, the exposure time was assigned the same way as for ChEI class; however, some patients transferred to other ChEI drug in the same or next intervals. We took into account the temporal nature of drug usage (eg, donepezil prescription first, then a prescription date of rivastigmine occurred the same year) and considered patients unexposed after the date of prescription fill of other medication (these patients were not kept exposed 1 year after the last known prescription fill). The exposure-time assignment is summarized in online supplementary figure 2 .

To assess the dose-response to ChEI class and specific drugs, we also extracted the prescribed daily doses (PDD) at the first date of prescription fill within each yearly interval (if a date was present).

\section{Propensity-score matched analysis}

To increase comparability, PS-matched user/non-user pairs were generated according to the exposure to ChEI, donepezil, rivastigmine, galantamine and relevant dose at the time of dementia diagnosis, or within the first year after dementia diagnoses.

Patients prescribed ChEI before dementia diagnosis (prevalent users) were excluded from both analyses.

Data from the Drug Registry on antidiabetics (ATC code A10-drugs used in diabetes), antipsychotics (N05A), hypnotics/sedatives (N05C), antithrombotic medication (B01) and drugs affecting cardiovascular system (C) were also extracted. Patients were considered users of medication if a drug was dispensed at the time or up to 3 years prior to dementia diagnosis.

\section{Swedish National Patient Registry (Patient Registry)}

The Patient Registry records all inpatient and specialized outpatient visits in Sweden, starting from 1987. ${ }^{20}$ The included diagnoses are coded according to the 10th version of the International Classification of Diseases (ICD-10). ${ }^{21}$ We extracted the information on patient records until December 31, 2014.

DM was identified by the ICD-10 code E10-E14 in the patient records or antidiabetic treatment (ATC code A10) prior to their dementia diagnosis. We did not differentiate between patients with type 1 or type $2 \mathrm{DM}$; however, the majority of patients are expected to be diagnosed with type $2 \mathrm{DM}$. Duration of DM was based on the difference between the date of dementia diagnosis and either the date of the earliest record in the Patient Register where a code E10-E14 occurred, or the earliest dispensation date of ATC code A10 from the Drug Register.

To adjust for the effect of additional diseases, we created a comorbidity index as devised by Charlson $e t$ $a l,{ }^{22}$ using the algorithm described by Quan $e t a l .{ }^{23}$ The ICD-10 codes for dementia were omitted as all patients were diagnosed with dementia. To avoid overadjustment, a separate comorbidity index was coded for patients with DM, excluding any DM-related ICD-10 codes.

\section{Swedish Cause of Death Registry (Death Registry)}

The Death Registry contains data starting 1952 and is the basis for official statistics on death causes in Sweden. ${ }^{24}$ The purpose of the registry is to describe the development of national all-cause and specific-cause mortality recording underlying and contributing causes of death based on the ICD-10 classification.

We extracted the information from the Death Registry since its initiation until the August 28, 2016-the end of the study follow-up. Overall mortality, cardiovascular mortality and diabetes-related mortality were counted if a valid record (patient death dated after dementia diagnosis) was present. Death from cardiovascular and cerebrovascular reasons was considered, if a patient had ICD-10 codes I00-I79 as the underlying (primary) cause of death. Death due to diabetes was considered if a patient had ICD-10 codes E10-E14 as underlying cause of death. Cardiovascular '(CV) mortality' and 'DM mortality' will be used as abbreviations for the two causes of death.

\section{Statistical analyses}

\section{Comparisons}

The main comparison was done between users and nonusers of ChEI among patients with DM and non-DM, respectively. To adjust for baseline differences, both adjustment for confounders in the regression models and PS matched cohorts were used. The PS was based on the variables: age at dementia diagnosis, gender, cohabitation, type of dementia diagnosis, MMSE score, Charlson comorbidity index at dementia diagnosis and cardiovascular, antithrombotic, antipsychotic and hypnotic/sedative medication at the time of dementia diagnosis or up to 3 years before. Patients with DM were also matched on the overall antidiabetic drug use at the time of dementia diagnosis or up to 3 years before and diabetes duration. Nearest-neighbor 1:1 PS matching without replacement using the caliper width of $0.2 \mathrm{SD}$ of the logit of PS was applied.

Using the PS matching in the DM cohort, we identified 999 ChEI user/nonuser pairs, 1246 donepezil pairs, 478 rivastigmine pairs and 516 galantamine pairs. In the non-DM cohort, we identified 5358 ChEI user/ nonuser pairs, 7942 donepezil pairs, 3363 rivastigmine pairs and 4157 galantamine pairs. Donepezil, rivastigmine and galantamine users were compared with nonusers of ChEI and users of the other ChEI (eg, donepezil user versus ChEI non-user or user of rivastigmine or 
galantamine-ergo more possible pairs for donepezil than for ChEI class).

To analyze dose-response, the PDD were divided into two groups (low and high dose) by splitting on the 50th percentile of the PDD received. The low-dose group comprised of PDD lower and including 50th percentile, with high-dose group comprising doses above the 50th percentile.

\section{Description}

The baseline characteristics of the populations are presented as means (SD) or medians (IQR) for continuous variables or number of patients (percentage) for categorical variables. The normality of distribution for continuous variables has been assessed using the Kolmogorov-Smirnov test. Populations were compared using $\chi^{2}$ test for binary variables and unpaired t-test and analysis of variance for continuous variables. When the assumptions of normality were not met, we used nonparametric test equivalents.

\section{Survival analysis}

Patients were included in the study from the date of their dementia diagnosis until their date of death or end of follow-up (August 28, 2016), whichever came first. The time scale used was time since entry (date of dementia diagnosis) for all analyses.

Cox-regression models were used to determine HRs with $95 \%$ CIs for the overall mortality in the users and non-users of ChEI. Competing risk regression models according to Fine and Gray ${ }^{25}$ were used to produce subdistribution HRs and compare the effect of ChEI usage on specific-cause mortality with other-cause mortality as competing risk. As the prescription of medication was considered also after the start of follow-up, ChEI usage and dose-response were entered into the regression models as time-varying covariates.

We analyzed the ChEI effect on mortality in the whole cohort and in the PS-matched cohorts.

In the whole cohort, we used two regression models with increasing level of confounder adjustment. In the unadjusted models, each predictor was entered separately. In the adjusted model, the confounders were entered concurrently. The analysis of patients without DM included these variables: age at dementia diagnosis, sex, MMSE score, dementia type, cohabitation (living alone, living with another adult, at nursing home), Charlson comorbidity score at dementia diagnosis, cardiovascular, antithrombotic, antipsychotic and hypnotic/sedative medication at the time of dementia diagnosis or up to 3 years before and ChEI. The analysis of patients with DM had been additionally adjusted for the use of antidiabetic medication at the time of dementia diagnosis or up to 3 years before and diabetes duration.

Due to some residual differences in the matched cohorts based on class ChEI usage, we adjusted for age and MMSE score in the matched analysis of ChEI in non-DM and for age and dementia type in DM cohort.
Survival data are presented as medians with 95\% CIs, HRs with $95 \%$ CIs or subdistribution HRs (sHR) with 95\% CIs in the competing risk analysis.

Data were analyzed using SPSS V.23 (IBM, Armonk, New York, USA) and SAS V.9.4 (SAS Institute, Cary, North Carolina, USA).

\section{Ethical considerations}

This study complies with the Declaration of Helsinki and was approved by the regional ethical committee in Stockholm, Sweden (number of the ethical approval: 2015/1313-32).

\section{RESULTS}

\section{Population description}

After excluding patients with duplicitous records, prevalent users, patients with missing information on drug use and other dementia types than $\mathrm{AD}$ or mixed-pathology dementia, we narrowed down the final study population to 22660 patients. The patients with a prior diagnosis of DM amounted to 3176 patients (14\%) (online supplementary figure 1 ).

In total, $2110(66.4 \%)$ patients with DM were users of ChEI compared with 14070 (72.2\%) patients without DM. Multiple significant differences existed between the users and non-users of ChEI, in both DM and non-DM cohorts (table 1). Most notably, the users were significantly younger at the time of dementia diagnosis (78.1 vs 81.4 years in the DM group, 78 vs 83 in the non-DM group), were less frequently at nursing homes $(3.8 \%$ vs $11.5 \%$ in DM, $3.4 \%$ vs $10.8 \%$ in non-DM) and had higher median MMSE scores (22 vs 20 both groups). In addition, the prevalence of mixed-pathology dementia was lower in the ChEI users ( $42 \%$ vs $65.9 \%$ in DM, $31.5 \%$ vs $54.3 \%$ in non-DM). The exposure to specific drugs and mortality rates are also summarized in table 1 .

After PS matching, the differences between users and non-users of ChEI were substantially reduced and with the exceptions of age at dementia diagnosis, dementia type and MMSE score all standardized mean differences were less than 0.1 SD. In PS-matched cohorts of specific drugs all differences were below 0.1 SD. The baseline characteristics of the PS-matched cohorts are summarized in table 1 and online supplementary tables 2-4.

\section{All-cause mortality and dose-response}

The all-cause mortality rates are summarized in the tables 2 and 3.

In the whole cohort, ChEI use was associated with $30 \%$ mortality reduction in the DM group $(0.70(0.62$ to 0.79$))$ and $32 \%$ in the non-DM group (0.68 (0.65 to 0.72$))$. Donepezil use was associated with $24 \%$ mortality reduction $(0.76$ (0.66 to 0.88$)$ ) in the DM group and $31 \%$ (0.69 (0.65 to $0.73)$ ) in the non-DM group, while galantamine was associated with $32 \%$ reduction in the DM group (0.68 (0.57 to 0.81$)$ ) compared with $26 \%$ in the patients without DM (0.74 (0.69 to 0.80$))$. Rivastigmine was associated with lower mortality only in the non-DM group (0.82 (0.75 to 0.89$))$. 


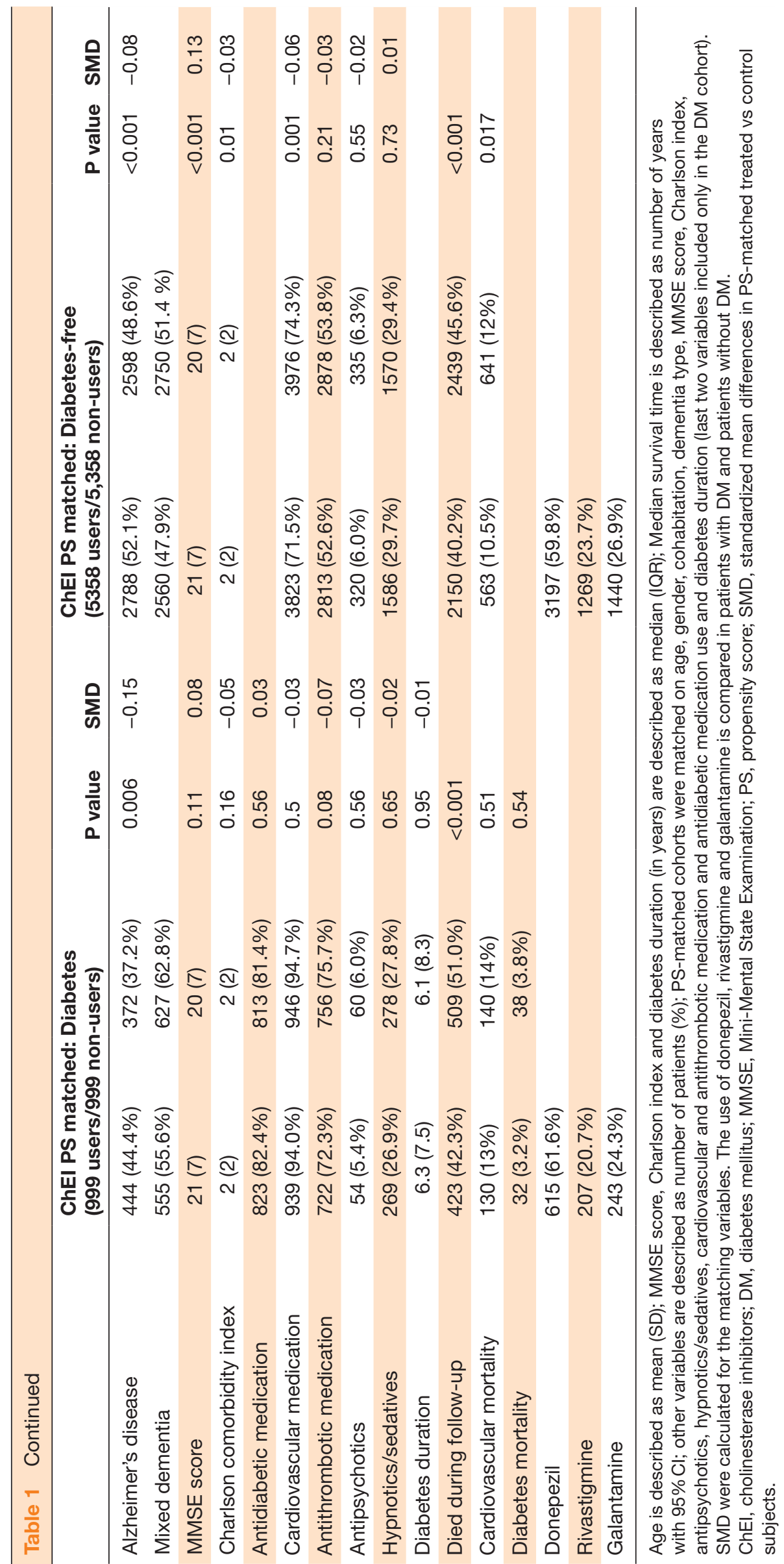


Table 2 All-cause mortality in patients with dementia by DM status and general ChEl use

\begin{tabular}{|c|c|c|}
\hline & \multicolumn{2}{|c|}{ Diabetes and dementia HR $(95 \% \mathrm{Cl})$} \\
\hline & Model 0 & Model 1 \\
\hline Age & $1.08(1.07 \text { to } 1.09)^{\star \star}$ & $1.06(1.05 \text { to } 1.07)^{\star \star}$ \\
\hline Male sex & $1.30(1.16 \text { to } 1.44)^{\star \star}$ & $1.53(1.36 \text { to } 1.72)^{\star \star}$ \\
\hline \multicolumn{3}{|l|}{ Dementia } \\
\hline$A D$ & Reference & Reference \\
\hline Mixed & $1.50(1.35 \text { to } 1.67)^{\star \star}$ & $1.17(1.04 \text { to } 1.30)^{\star}$ \\
\hline \multicolumn{3}{|l|}{ Cohabitation } \\
\hline Living alone & Reference & Reference \\
\hline Living with an adult & $0.80(0.71 \text { to } 0.89)^{\star \star}$ & $0.84(0.75 \text { to } 0.96)^{\star}$ \\
\hline At nursing home & $2.20(1.83 \text { to } 2.66)^{\star \star}$ & $1.33(1.09 \text { to } 1.62)^{\star}$ \\
\hline MMSE score & $0.93(0.93 \text { to } 0.94)^{\star \star}$ & $0.95(0.94 \text { to } 0.96)^{\star \star}$ \\
\hline Charlson comorbidity index & $1.18(1.15 \text { to } 1.22)^{\star \star}$ & $1.11(1.08 \text { to } 1.14)^{\star \star}$ \\
\hline Antidiabetic medication & $0.92(0.80$ to 1.06$)$ & $1.06(0.92$ to 1.21$)$ \\
\hline Cardiovascular medication & $1.28(1.03 \text { to } 1.60)^{\star}$ & $1.13(0.90$ to 1.41$)$ \\
\hline Antithrombotic medication & $1.41(1.24 \text { to } 1.59)^{\star \star}$ & 1.05 (0.92 to 1.20$)$ \\
\hline Antipsychotics & $1.32(1.05 \text { to } 1.65)^{\star}$ & 0.99 (0.79 to 1.25$)$ \\
\hline Hypnotics/sedatives & $1.19(1.06 \text { to } 1.34)^{\star}$ & 1.00 (0.89 to 1.14$)$ \\
\hline Diabetes duration & $1.01(1.01 \text { to } 1.02)^{\star}$ & $1.01(1.01 \text { to } 1.02)^{\star}$ \\
\hline ChEl & $0.51(0.45 \text { to } 0.57)^{\star \star}$ & $0.70(0.62 \text { to } 0.79)^{\star \star}$ \\
\hline \multirow[t]{3}{*}{ ChEI-PS-matched } & $0.76(0.67 \text { to } 0.86)^{\star \star}$ & \\
\hline & \multicolumn{2}{|c|}{ Diabetes-free and dementia HR $(95 \% \mathrm{Cl})$} \\
\hline & Model 0 & Model 1 \\
\hline Age & $1.08(1.08 \text { to } 1.09)^{\star *}$ & $1.06(1.06 \text { to } 1.07)^{\star *}$ \\
\hline Male sex & $1.31(1.25 \text { to } 1.38)^{\star \star}$ & $1.48(1.40 \text { to } 1.56)^{\star \star}$ \\
\hline \multicolumn{3}{|l|}{ Dementia } \\
\hline$A D$ & Reference & Reference \\
\hline Mixed & $1.65(1.57 \text { to } 1.73)^{\star \star}$ & $1.16(1.10 \text { to } 1.22)^{\star \star}$ \\
\hline \multicolumn{3}{|l|}{ Cohabitation } \\
\hline Living alone & Reference & Reference \\
\hline Living with an adult & $0.78(0.74 \text { to } 0.82)^{\star \star}$ & $0.94(0.89 \text { to } 0.99)^{*}$ \\
\hline At nursing home & $1.99(1.82 \text { to } 2.16)^{\star *}$ & $1.27(1.17 \text { to } 1.39)^{\star \star}$ \\
\hline MMSE score & $0.93(0.93 \text { to } 0.93)^{\star \star}$ & $0.94(0.94 \text { to } 0.95)^{\star \star}$ \\
\hline Charlson comorbidity index & $1.19(1.18 \text { to } 1.21)^{\star \star}$ & $1.14(1.12 \text { to } 1.16)^{\star \star}$ \\
\hline Cardiovascular medication & $1.40(1.33 \text { to } 1.47)^{\star \star}$ & 1.04 (0.98 to 1.10$)$ \\
\hline Antithrombotic medication & $1.55(1.48 \text { to } 1.62)^{\star \star}$ & $1.10(1.04 \text { to } 1.16)^{\star}$ \\
\hline Antipsychotics & $1.57(1.44 \text { to } 1.72)^{\star \star}$ & $1.18(1.07 \text { to } 1.30)^{*}$ \\
\hline Hypnotics/sedatives & $1.23(1.17 \text { to } 1.30)^{\star \star}$ & 1.04 (0.99 to 1.10$)$ \\
\hline ChEl & $0.46(0.44 \text { to } 0.48)^{\star \star}$ & $0.68(0.65 \text { to } 0.72)^{\star *}$ \\
\hline ChEI-PS-matched & $0.80(0.75 \text { to } 0.84)^{\star \star}$ & \\
\hline
\end{tabular}

Model 0 was unadjusted; Model one was adjusted for all predictors included in the table; PS-matched analysis is adjusted for age and MMSE in the DiabetesFree cohort and for age and dementia type in the Diabetes cohort due to residual differences in the matched cohorts.

${ }^{*} \mathrm{P}<0.05 ;{ }^{* *} \mathrm{P}<0.001$.

$A D$, Alzheimer's disease; ChEl, cholinesterase inhibitors; Mixed, mixedpathology dementia; MMSE, Mini-Mental State Examination; PS, propensity score.

In the PS-matched analysis, ChEI use was associated with $24 \%$ mortality reduction $(0.76(0.67$ to 0.86$))$ in patients with DM, compared with $20 \%(0.80$ (0.75 to $0.84)$ ) in patients without DM. The association between donepezil and mortality reduction was similar in both
DM (0.84 (0.74 to 0.96)) and non-DM group (0.85 (0.80 to 0.90$)$ ), while galantamine was associated with $20 \%$ mortality reduction in patients with DM $(0.80$ (0.66 to $0.97)$ ) and $7 \%$ in the patients without DM (0.93 (0.86 to 0.99)).

When compared with the low-dose group, the highdose group was not significantly associated with improved mortality in any of the analysis. Non-users had consistently higher mortality rates in almost all analyses, with the exception of rivastigmine in the PS-matched analysis (online supplementary table 1 ).

\section{Cardiovascular and diabetes mortality}

Table 4 represents the analysis of $\mathrm{CV}$ and DM mortality based on the Fine and Gray models. In the adjusted wholecohort analysis, ChEI class, donepezil and rivastigmine were significantly associated with $\mathrm{CV}$ mortality reduction, but only in the non-DM group (23\%, 27\% and 22\% reductions, respectively). Conversely, only donepezil was found protective in the non-DM matched analysis $(0.79$ ( 0.71 to 0.89)).

ChEI use was associated with $48 \%$ reduction in DM mortality (0.52 (0.32 to 0.87$)$ ); however, no specific drug confirmed the reduction found in the ChEI class.

Neither the ChEI class nor specific ChEI were associated with reductions in DM mortality in the matched analysis.

\section{DISCUSSION}

Our aim was to study the effectiveness of clinical ChEI treatment on survival in patients with DM with dementia as well as in patients without DM with dementia. The results of our study suggest that ChEI use is associated with a lower all-cause mortality rates regardless of DM status, while only donepezil and galantamine were associated with lower mortality in patients with DM. In addition, we found a reduction in diabetes-related mortality associated with the class-effect of ChEI. Last, higher ChEI doses were not associated with more pronounced mortality reduction compared with low-dose groups.

ChEI have been the first-line symptomatic treatment for $\mathrm{AD}$ since the late 1990s; therefore, the clinical experience with them is quite extensive. However, to our knowledge this is the first study considering such a large exposure window and stratification by DM status.

A sizeable majority of the DM cohort was prescribed ChEI; however, still significantly less than in the patients without DM, corroborating our previous results. ${ }^{14}$ Nevertheless, ChEI use appeared to improve survival in both DM and non-DM group in a comparable rate (between $24 \%$ and $30 \%$ and $20 \%$ and $32 \%$, respectively, based on PS matched and whole-cohort analyses), suggesting that patients with DM may benefit from ChEI use to a similar extent as non-DM users.

The effect of ChEI through the whole course of dementia is not fully understood. Their effect seems dependent on the clinical stage and duration of treatment, with the most benefit found in the mild and 
Table 3 All-cause mortality in users of specific cholinesterase inhibitors by diabetes status

Diabetes and dementia HR $(95 \% \mathrm{CI})$

\begin{tabular}{|c|c|c|c|}
\hline & & & \\
\hline & Model 0 & Model 1 & PS matched \\
\hline Donepezil & $0.63(0.55 \text { to } 0.72)^{\star \star}$ & $0.76(0.66 \text { to } 0.88)^{\star \star}$ & $0.84(0.74 \text { to } 0.96)^{*}$ \\
\hline Rivastigmine & $0.68(0.56 \text { to } 0.83)^{\star \star}$ & 0.88 (0.72 to 1.07$)$ & 0.97 (0.79 to 1.20$)$ \\
\hline \multirow[t]{3}{*}{ Galantamine } & $0.57(0.48 \text { to } 0.67)^{\star \star}$ & $0.68(0.57 \text { to } 0.81)^{\star *}$ & $0.80(0.66 \text { to } 0.97)^{\star}$ \\
\hline & \multicolumn{3}{|c|}{ Diabetes-free and dementia HR $(95 \% \mathrm{Cl})$} \\
\hline & Model 0 & Model 1 & PS matched \\
\hline Donepezil & $0.59(0.56 \text { to } 0.63)^{\star \star}$ & $0.69(0.65 \text { to } 0.73)^{\star \star}$ & $0.85(0.80 \text { to } 0.90)^{\star \star}$ \\
\hline Rivastigmine & $0.61(0.56 \text { to } 0.66)^{\star \star}$ & $0.82(0.75 \text { to } 0.89)^{\star \star}$ & 1.03 (0.95 to 1.12$)$ \\
\hline Galantamine & $0.55(0.51 \text { to } 0.59)^{\star \star}$ & $0.74(0.69 \text { to } 0.80)^{\star \star}$ & $0.93(0.86 \text { to } 0.99)^{*}$ \\
\hline
\end{tabular}

Model 0 was unadjusted; Model 1 was adjusted for age at dementia diagnosis, gender, dementia type, cohabitation, Mini-Mental State Examination score, Charlson comorbidity index, antipsychotics, hypnotics/sedatives, cardiovascular and antithrombotic medication; Model 1 for the analysis in patients with diabetes and dementia was additionally adjusted for the use of antidiabetic medication and diabetes duration.

${ }^{*} \mathrm{P}<0.05 ;{ }^{*} \mathrm{P}<0.001$.

PS, propensity score.

moderate stages of dementia ${ }^{5}$ and longer duration of treatment. ${ }^{26}$ However, ChEI have been shown to be effective also in nursing-home patients. ${ }^{27}$ The average survival of patients with DM was 1 year shorter compared with patients without DM, concurring with a generally higher mortality in patients with $\mathrm{DM},{ }^{28}{ }^{29}$ and the average survival times in patients with dementia. ${ }^{30}$ Thus, patients with DM could benefit from the ChEI use for a shorter period in absolute terms. Second, treating DM in patient with cognitive dysfunction is challenging, ${ }^{31}$ and the stabilizing effect of ChEI on cognition could additionally aid the self-management of DM. Moreover, ChEI use can delay the placement of patients to nursing homes,${ }^{32}$ which could provide stronger benefit to patients with DM, as living at nursing home was a stronger predictor of mortality in patients with DM, and DM is a strong risk factor for institutionalization. ${ }^{33}$ On the other hand, a 2019 meta-analysis of randomized controlled trials (RCTs) concluded no significant effect of ChEI on cognition and suggested no further clinical trials are necessary. ${ }^{34}$ However, the average duration of RCTs included was quite short-approximately 30 weeks, with few RCTs lasting 8 months. The effect on cognition over longer duration may still be of clinical relevance in a dementia disorder lasting 8-10 years. Moreover, the meta-analysis could not conclude any effect on mortality, citing need for high-quality observational studies.

Interestingly, there is increasing evidence linking the ChEI use to cardiovascular and cerebrovascular protection. A recent meta-analysis of 9 cohort studies found a $37 \%$ reduction in cardiovascular events, including stroke, myocardial infarction, acute coronary syndrome and cardiovascular mortality, ${ }^{35}$ and it is plausible that patients with DM may also benefit from this protective effect. The meta-analysis by Isik and colleagues also found higher prevalence of bradycardia and hypertension in ChEI users, which could counteract the appropriateness of ChEI use in patients with DM. Moreover, a common complication of DM management-hypoglycemia-can lead to multiple arrhythmias ${ }^{36}$ therefore, this subject should be further investigated. Furthermore, ChEI use is associated with weight loss that is partly attributable to gastrointestinal side-effects. ${ }^{5}$ Weight loss in dementia patients with DM should be approached carefully as it can act as a double-edged sword-improving glycemic control on one side ${ }^{37}$ and increasing the potential for malnutrition and hypoglycemia on the other. ${ }^{38}$

The analyses of specific ChEI drugs brought generally favorable results for donepezil, which was associated with improved mortality rates in both patients with DM and non-DM. Donepezil was the most commonly prescribed ChEI, which probably reflects that it was the first approved ChEI and is better tolerated compared with galantamine and rivastigmine's oral form. ${ }^{11}$ In addition, we found that donepezil was the only ChEI consistently associated with reduction in cardiovascular mortality, corroborating previous data on cardiovascular and cerebrovascular outcomes from Nordström, Tan and others. ${ }^{7835}$ Hwang and colleagues also found anti-inflammatory effects in donepezil treatment, however only in high doses. ${ }^{39}$

We found some evidence toward mortality reduction in rivastigmine; however, this was not consistent and limited to patients without DM. The lack of association between rivastigmine and mortality in patients with $\mathrm{DM}$ is in contrast to studies concluding its benefits in inhibiting both acetyl- and butyrylcholinesterase,${ }^{40}$ as well as rivastigmine's alternative administration method-the transdermal patch - which avoids the cholinergic peaks and improves safety and tolerability. ${ }^{42}$ On the other hand, accidental applications of multiple rivastigmine patches could lead to carbamate-like poisoning and 


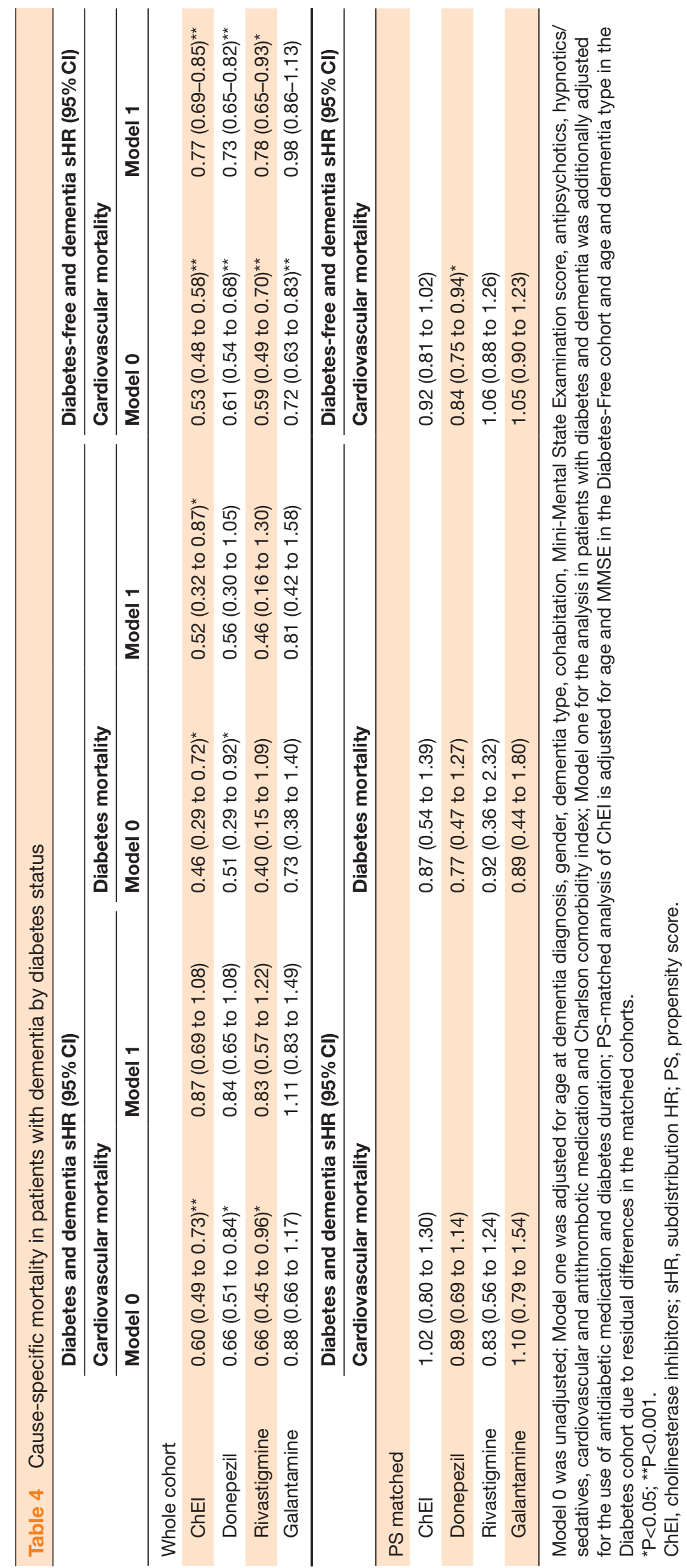


death. ${ }^{43}$ This could be more pronounced in polymedicated patients and with increased dementia severity (such as patients with DM); however, we could not stratify on rivastigmine's delivery methods in our study.

Galantamine use was associated with a clear reduction of mortality in patients with DM (32\% whole-cohort, $20 \%$ matched cohort). Its possible benefit for patients with DM could lie in the galantamine's allosteric potentiation of alpha-7 nicotinic receptors. These receptors are involved in the cholinergic anti-inflammatory pathway and can attenuate macrophage and microglial response to cytokines. ${ }^{44}{ }^{45}$ In addition, a recent small clinical trial reported alleviation of insulin resistance and peripheral anti-inflammatory effect in galantamine users with metabolic syndrome. ${ }^{46}$ Both systemic and neuroinflammation are common to patients with type $2 \mathrm{DM} ;{ }^{47}$ therefore, the relatively higher mortality reduction in DM users might be due to galantamine's unique profile. On the other hand, more common adverse reactions compared with donepezil could predispose galantamine use to a specific group of patients with dementia able to withstand the side-effects and benefit from its pharmacodynamics.

We did not observe a dose-response effect in all-cause mortality analyses, suggesting that lower doses provide similar benefit. This is in contrast to previous studies; ${ }^{78}$ however, we used a different grouping method and also took into account the possibility of changing doses with advancing time. High-dose rivastigmine and galantamine in the non-DM cohorts were associated with higher mortality; however, the matched and wholecohort analyses were discordant. Therefore, it is more likely that the ChEI dose side-effect/benefit ratio plays a similar role in both DM and non-DM groups.

ChEI as a class seemed to reduce DM mortality; however, this was not corroborated in the matched analysis, likely due to small number of events. We believe that more work on the subject is needed, as DM is less frequently included as underlying cause of death by physicians. ${ }^{24}$ On the other hand, there is no reason why DM should be reported less frequently as underlying cause of death in ChEI users; thus, further studies should determine whether cognitive stabilization or cardiovascular protection due to ChEI use helps maintain $\mathrm{HbA}_{1 \mathrm{c}}$ targets of patients with DM or prevents hypoglycemic episodes.

In conclusion, our study brings evidence that ChEI use is associated with mortality reduction in patients with DM with AD or mixed-pathology dementia, with specifically galantamine and donepezil having potential benefit. Future studies should investigate, whether a "prescription hierarchy" for patients with dementia could be created with the aim of advising caregivers on which drugs to use and which to omit.

\section{Strengths and weaknesses}

Our study is strengthened by the long-term exposure window and follow-up, large sample size and the national coverage of the registers. In addition, data stored in the Drug Registry offers a close reflection of the prescription fills recorded in every Swedish pharmacy. On the other hand, certain drawbacks need to be addressed.

We used non-randomized observational data and therefore we could not assess causal links. Moreover, residual confounding that we could not account for (eg, level of DM control) could affect mortality rates and as in all pharmaco-epidemiological studies, confounding by indication needs to be considered as potential source of bias. Ergo, it is not possible in this observational setting to account for the clinical decision-making and overall patient health, even though the matching and adjustment provide increased comparability between the user/nonuser pairs.

SveDem is connected to all specialist memory clinics in Sweden and to increasing number of primary care centers and nursing homes. ${ }^{17} 48$ Still, the coverage of incident dementia has been previously estimated to $36 \%$, which somewhat hinders the ability to generalize the results to the entire Swedish dementia population. ${ }^{17}$ However, other studies reported younger, healthier populations with higher socioeconomic status to be more commonly registered to quality registers, meaning our results also likely can be extrapolated to such patients. ${ }^{49}$ Unfortunately, it is difficult to gather the frailest dementia population, due to inherent nature of the disease and lower contact with healthcare.

The completeness of the Death Registry is good, with almost $100 \%$ ascertainment of all-cause mortality. However, approximately $16 \%$ of the underlying causes of death were missing in both DM and non-DM populations, which could bias the cause-specific mortality rates, but in an unknown manner. Physicians are generally advised to input the condition that led directly to death as the underlying cause, which would mean more frequent records of cardiovascular and cerebrovascular conditions like stroke or myocardial infarction. ${ }^{24}$

Overall, we believe that our study results could be applied to a large population of patients with DM and dementia, but probably a somewhat healthier group. ${ }^{49}$

\section{Author affiliations}

${ }^{1}$ Division of Clinical Geriatrics, Center for Alzheimer Research, Department of Neurobiology, Care Sciences and Society, Karolinska Institute, Huddinge, Sweden ${ }^{2}$ Growth and Metabolism, Department of Molecular Medicine and Surgery, Karolinska Institute, Stockholm, Sweden

${ }^{3}$ Institute of Environmental Medicine, Karolinska Institute, Stockholm, Sweden ${ }^{4}$ Aging Research Center, Center for Alzheimer Research, Department of Neurobiology, Care Sciences and Society, Karolinska Institute, Stockholm, Sweden ${ }^{5}$ Division of Neurogeriatrics, Center for Alzheimer Research, Department of Neurobiology, Care Sciences and Society, Karolinska Institute, Stockholm, Sweden

${ }^{6}$ Theme Aging, Karolinska University Hospital, Huddinge, Sweden

${ }^{7}$ Section for Neurology, Department of Internal Medicine, Södersjukhuset Stockholm South General Hospital, Stockholm, Sweden

Acknowledgements We would like to thank all patients, caregivers and staff for providing their information to the registry.

Contributors ES analyzed the data and codesigned the study. MA contributed to the introduction and discussion. NH suggested the statistical methods and 
contributed to discussion. JF extracted the data from the Drug Registry. BW interpreted the data and contributed to the discussion. SG-P kindly provided all raw registry data. DR and ME supervised and codesigned the study. JS designed the study, analyzed the data and wrote the manuscript. All authors have reviewed the manuscript's content and approved of its final version.

Funding This study has been supported by the Swedish Brain Power, Swedish Research Council (grant numbers 2012-2291, 2016-02317, 2018-02843), Alzheimerfonden, CIMED, Stockholm County Council (ALF project), the Swedish Associations of Local Authorities and Regions, the Swedish Order of Saint John/ Johanniterorden, Swedish Society for Medical Research, FORTE (the Swedish Council for Health, Working Life and Welfare, dnr: 2017-01646), the Swedish Stroke Association, Margaretha af Ugglas Foundation and the Stiftelsen för Gamla Tjänarinnor.

Competing interests None declared.

Patient consent for publication Not required.

Ethics approval Regional ethical committee in Stockholm, Sweden (2015/1313-32).

Provenance and peer review Not commissioned; externally peer reviewed.

Data availability statement No data are available. The entities responsible for the original data and the Swedish law do not allow for sharing of the data from the Swedish national or quality-of-care registers.

Open access This is an open access article distributed in accordance with the Creative Commons Attribution Non Commercial (CC BY-NC 4.0) license, which permits others to distribute, remix, adapt, build upon this work non-commercially, and license their derivative works on different terms, provided the original work is properly cited, appropriate credit is given, any changes made indicated, and the use is non-commercial. See: http://creativecommons.org/licenses/by-nc/4.0/.

ORCID iD

Juraj Secnik http://orcid.org/0000-0002-1532-3967

\section{REFERENCES}

1 The Lancet. Making more of multimorbidity: an emerging priority. Lancet 2018:391:1637.

2 Bunn F, Burn A-M, Goodman C, et al. Comorbidity and dementia: a scoping review of the literature. BMC Med 2014;12:192.

3 Biessels GJ, Staekenborg S, Brunner E, et al. Risk of dementia in diabetes mellitus: a systematic review. Lancet Neurol 2006;5:64-74.

4 American Diabetes Association. Standards Of Medical Care in Diabetes - 2018. Diabetes Care 2018:41:172.

5 Buckley JS, Salpeter SR. A risk-benefit assessment of dementia medications: systematic review of the evidence. Drugs Aging 2015;32:453-67.

6 Wallin AK, Andreasen N, Eriksson S, et al. Donepezil in Alzheimer's disease: what to expect after 3 years of treatment in a routine clinical setting. Dement Geriatr Cogn Disord 2007;23:150-60.

7 Tan ECK, Johnell K, Garcia-Ptacek S, et al. Acetylcholinesterase inhibitors and risk of stroke and death in people with dementia. Alzheimers Dement 2018;14:944-51.

8 Nordström P, Religa D, Wimo A, et al. The use of cholinesterase inhibitors and the risk of myocardial infarction and death: a nationwide cohort study in subjects with Alzheimer's disease. Eur Heart $J$ 2013;34:2585-91.

9 Lin Y-T, Wu P-H, Chen C-S, et al. Association between acetylcholinesterase inhibitors and risk of stroke in patients with dementia. Sci Rep 2016;6:29266.

10 Ali TB, Schleret TR, Reilly BM, et al. Adverse effects of cholinesterase inhibitors in dementia, according to the pharmacovigilance databases of the United-States and Canada. PLoS One 2015;10:e0144337.

11 Lockhart IA, Mitchell SA, Kelly S. Safety and tolerability of donepezil, rivastigmine and galantamine for patients with Alzheimer's disease: systematic review of the 'real-world' evidence. Dement Geriatr Cogn Disord 2009;28:389-403.

12 Colovic MB, Krstic DZ, Lazarevic-Pasti TD, et al. Acetylcholinesterase inhibitors: pharmacology and toxicology. Curr Neuropharmacol 2013;11:315-35.

13 Ago Y, Koda K, Takuma K, et al. Pharmacological aspects of the acetylcholinesterase inhibitor galantamine. J Pharmacol Sci 2011;116:6-17.

14 Secnik J, Cermakova P, Fereshtehnejad S-M, et al. Diabetes in a large dementia cohort: clinical characteristics and treatment from the Swedish dementia registry. Diabetes Care 2017;40:1159-66.
15 Socialstyrelsen NBoHaW. National guidelines for dementia health and social care. Support for governance and management / Nationella riktlinjer för vård och omsorg Vid demenssjukdom. Stöd för styrning och ledning, 2017. Available: https://www. socialstyrelsen.se/publikationer2017/2017-12-2

16 Biessels GJ, Despa F. Cognitive decline and dementia in diabetes mellitus: mechanisms and clinical implications. Nat Rev Endocrinol 2018;14:591-604.

17 Religa D, Fereshtehnejad S-M, Cermakova P, et al. SveDem, the Swedish Dementia Registry - a tool for improving the quality of diagnostics, treatment and care of dementia patients in clinical practice. PLoS One 2015;10:e0116538.

18 Eriksdotter M, Kåwe K, Kilander L, et al. Svenska demensregistret årsrapport 2017 [Swedish dementia registry yearly report 2017], 2018. Available: http://www.ucr.uu.se/svedem/om-svedem/ arsrapporter

19 Wettermark B, Hammar N, Fored CM, et al. The new Swedish Prescribed Drug Register--opportunities for pharmacoepidemiological research and experience from the first six months. Pharmacoepidemiol Drug Saf 2007:16:726-35.

20 Ludvigsson JF, Andersson E, Ekbom A, et al. External review and validation of the Swedish national inpatient register. BMC Public Health 2011;11:450.

21 World Health Organization. The International classification of diseases 10th revision (ICD-10); 1993.

22 Charlson ME, Pompei P, Ales KL, et al. A new method of classifying prognostic comorbidity in longitudinal studies: development and validation. J Chronic Dis 1987:40:373-83.

23 Quan $\mathrm{H}$, Sundararajan V, Halfon P, et al. Coding algorithms for defining comorbidities in ICD-9-CM and ICD-10 administrative data. Med Care 2005:43:1130-9.

24 Brooke HL, Talbäck M, Hörnblad J, et al. The Swedish cause of death register. Eur J Epidemiol 2017;32:765-73.

25 Fine JP, Gray RJ. A proportional hazards model for the Subdistribution of a competing risk. J Am Stat Assoc 1999;94:496-509.

26 Wattmo C, Londos E, Minthon L. Longitudinal associations between survival in Alzheimer's disease and cholinesterase inhibitor use, progression, and community-based services. Dement Geriatr Cogn Disord 2015;40:297-310.

27 Winblad B, Kilander L, Eriksson S, et al. Donepezil in patients with severe Alzheimer's disease: double-blind, parallel-group, placebocontrolled study. Lancet 2006;367:1057-65.

28 Bertoni AG, Krop JS, Anderson GF, et al. Diabetes-related morbidity and mortality in a national sample of U.S. elders. Diabetes Care 2002;25:471-5

29 Zimmet P, Alberti KG, Magliano DJ, et al. Diabetes mellitus statistics on prevalence and mortality: facts and fallacies. Nat Rev Endocrinol 2016;12:616-22.

30 Brodaty H, Seeher K, Gibson L. Dementia time to death: a systematic literature review on survival time and years of life lost in people with dementia. Int Psychogeriatr 2012;24:1034-45.

31 Munshi MN. Cognitive dysfunction in older adults with diabetes: what a clinician needs to know. Diabetes Care 2017:40:461-7.

32 Thompson S, Lanctôt KL, Herrmann N. The benefits and risks associated with cholinesterase inhibitor therapy in Alzheimer's disease. Expert Opin Drug Saf 2004;3:425-40.

33 Rodríguez-Sánchez B, Angelini V, Feenstra T, et al. DiabetesAssociated factors as predictors of nursing home admission and costs in the elderly across Europe. J Am Med Dir Assoc 2017;18:74-82

34 Blanco-Silvente L, Castells X, Garre-Olmo J, et al. Study of the strength of the evidence and the redundancy of the research on pharmacological treatment for Alzheimer's disease: a cumulative meta-analysis and trial sequential analysis. Eur J Clin Pharmacol 2019;75:1659-67.

35 Isik AT, Soysal P, Stubbs B, et al. Cardiovascular outcomes of cholinesterase inhibitors in individuals with dementia: a metaanalysis and systematic review. J Am Geriatr Soc 2018;66:1805-11.

36 Frier BM. Hypoglycaemia in diabetes mellitus: epidemiology and clinical implications. Nat Rev Endocrinol 2014;10:711-22.

37 Gummesson A, Nyman E, Knutsson M, et al. Effect of weight reduction on glycated haemoglobin in weight loss trials in patients with type 2 diabetes. Diabetes Obes Metab 2017;19:1295-305.

38 Miller SL, Wolfe RR. The danger of weight loss in the elderly. J Nutr Health Aging 2008;12:487-91.

39 Hwang $\mathrm{J}$, Hwang $\mathrm{H}$, Lee $\mathrm{H}-\mathrm{W}$, et al. Microglia signaling as a target of donepezil. Neuropharmacology 2010;58:1122-9.

40 Kandiah N, Pai M-C, Senanarong V, et al. Rivastigmine: the advantages of dual inhibition of acetylcholinesterase and butyrylcholinesterase and its role in subcortical vascular 
dementia and Parkinson's disease dementia. Clin Interv Aging 2017;12:697-707.

41 Winblad B, Machado JC. Use of rivastigmine transdermal patch in the treatment of Alzheimer's disease. Expert Opin Drug Deliv 2008;5:1377-86

42 Birks JS, Grimley Evans J. Rivastigmine for Alzheimer's disease. Cochrane Database Syst Rev 2015:CD001191.

43 Khoury R, Rajamanickam J, Grossberg GT. An update on the safety of current therapies for Alzheimer's disease: focus on rivastigmine. Ther Adv Drug Saf 2018;9:171-8.

44 Pavlov VA, Wang H, Czura CJ, et al. The cholinergic antiinflammatory pathway: a missing link in neuroimmunomodulation. Mol Med 2003;9:125-34.

45 Shytle RD, Mori T, Townsend K, et al. Cholinergic modulation of microglial activation by alpha 7 nicotinic receptors. J Neurochem 2004;89:337-43.
46 Consolim-Colombo FM, Sangaleti CT, Costa FO, et al. Galantamine alleviates inflammation and insulin resistance in patients with metabolic syndrome in a randomized trial. JCl Insight 2017;2. doi:10.1172/jci.insight.93340. [Epub ahead of print: 20 Jul 2017].

47 Wong CHY, Wanrooy BJ, Bruce DG. Chapter 10 Neuroinflammation, Type 2 Diabetes, and Dementia. Type 2 Diabetes and Dementia 2018:195-209.

48 Eriksdotter M, Kilander L, Mattsson UB, et al. Svenska demensregistret årsrapport 2016 [The Swedish dementia registry yearly report], 2017. Available: http://www.ucr.uu.se/svedem/omsvedem/arsrapporter

49 Aspberg S, Stenestrand U, Köster M, et al. Large differences between patients with acute myocardial infarction included in two Swedish health registers. Scand J Public Health 2013;41:637-43. 